\title{
Entre la experimentada acción de amparo mexicana y la adolescente acción de tutela colombiana: algunos semblantes críticos*
}

Between the Experienced Mexican Protective Action and the Adolescent Colombian Tutelage Action: Some Critical Aspects

\section{Eudoro Echeverri Quintana**}

\section{RESUMEN}

Este estudio analiza la acción de amparo en México, como contribución extraordinaria al constitucionalismo moderno, y de la acción de tutela en Colombia. En el estudio comparativo observo criticamente dos cuestiones: en México, estimo equivocada la procedencia del juicio de amparo contra "normas generales", porque considero que es tarea propia de los jueces al interior del proceso de control de constitucionalidad. En Colombia aprecio que, erróneamente, la Corte Constitucional aniquiló el ejercicio de la acción de tutela al inventar el requisito de la inmediatez con una jurisprudencia ambivalente y confusa. Debia intentarse en un término razonable y proporcionado, contado a partir de la vulneración o amenaza al derecho fundamental comprometido.

PALABRAS CLAVE: Juicio de amparo, acción de tutela, derechos fundamentales.

\begin{abstract}
The study analyses the Protective Action in Mexico, as an extraordinary contribution to modern constitutionalism, and the Tutelage Action in Colombia. In the comparative study I look critically at two questions. I think that the origin of the Amparo Proceeding against "general standards" in Mexico is wrong, because it is a work of judges in constitutionality control process. In Colombia, in respect of the Tutelage Action, the Constitutional Court annihilated, mistakenly, its exercise after the requirement of the immediacy was invented, with an ambivalent and confused jurisprudence.
\end{abstract}

KEY WORDS: Amparo proceeding, tutelage action, fundamental rights.

\footnotetext{
* Artículo recibido el 4 de abril de 2016 y aceptado para su publicación el 2 de mayo de 2016.

** Profesor de espacializaciones y maestrias en Derecho Constitucional, Penal y Derechos Humanos en la Universidad Libre de Colombia-Pereira. (euecheverri@yahoo.com).
} 


\section{SUMARIO}

1. Introducción

2. Origen internacional de la acción de tutela o de amparo

3. Un inconveniente en el ejercicio de la acción de tutela en Colombia

4. Una dificultad en el ejercicio de la acción de amparo en México

5. Conclusiones

\section{Introducción}

Los propósitos de esta investigación son rendir tributo al aporte mundial del derecho constitucional por parte de México con la acción de amparo -como siempre lo he destacado en la academia-, y aprovechar la oportunidad para establecer paralelos con Colombia con la acción de tutela, acerca de tan importante medio en la defensa de derechos y garantías. Dicho país también en otros senderos del derecho constitucional ha contribuido al desarrollo, como sucedió en la materia de las cláusulas de intangibilidad o pétreas en la Constitución de Colombia de $1821 .^{1}$ Valga decir que en Colombia la Corte Constitucional ha asumido como equivalentes los términos acción de tutela y acción de amparo. ${ }^{2}$

Estos ágiles mecanismos son ciertamente un control de constitucionalidad en el sentido de mantener ilesa la majestad de la Constitución y conjurar todo conato de atropello de gobernantes o particulares que prestan servicios públicos. Pero su regulación puntual es el ideal en una sociedad democrática.

\footnotetext{
${ }^{1}$ Artículo 190. "En cualquier tiempo en que las dos terceras partes de cada una de las dos Cámaras juzguen conveniente la reforma de algunos artículos de esta Constitución, podrá el Congreso proponerla para que de nuevo se tome en consideración, cuando se haya renovado, por lo menos, la mitad de los miembros de las Cámaras que propusieron la reforma; y si entonces fuere también ratificada por los dos tercios de cada una, procediéndose con las formalidades prescritas en la Sección 1 del Título IV, será válida y hará parte de la Constitución; pero nunca podrán alterarse las bases contenidas en la Sección 1 del Título l y en la 2 del Título II" (cursivas del autor). La Sección primera del título I abarcaba los artículos del 1 al 3 y se referian a que la nación colombiana era para siempre irrevocablemente libre e independiente de la monarquía española y de cualquier otra potencia o dominación extranjera y nunca será patrimonio de ninguna familia ni persona. La soberania residia esencialmente en la nación y los magistrados y oficiales del Gobierno, investidos de cualquiera especie de autoridad, son sus agentes o comisarios, y responden a ella de su conducta pública. Era un deber de la nación proteger por leyes sabias y equitativas la libertad, la seguridad, la propiedad y la igualdad de todos los colombianos. La Sección segunda del título II comprendía los artículos del 9 al 11: El Gobierno de Colombia era popular representativo. El pueblo no ejercerá por sí mismo otras atribuciones de la soberanía que la de las elecciones primarias, ni depositará el ejercicio de ella en unas solas manos. El Poder Supremo estará dividido para su administración en Legislativo, Ejecutivo y Judicial. El poder de dar leyes corresponde al Congreso; el de hacer que se ejecuten, al presidente de la república, y el de aplicarlas en las causas civiles y criminales, a los tribunales y juzgados.

${ }^{2}$ Sentencias T-653 de 2012 y T-265 de 2014.
} 
Específicamente, se atribuye el nacimiento de la acción de amparo en México a la expedición de la Constitución de Yucatán de 1841. Sin embargo, se cristalizó en la Constitución de 1857. ${ }^{3}$ Pero fue en la gloriosa Constitución de Querétaro de 1917 cuando se materializó en el artículo 107.

En Colombia, concretamente la figura en comento se intentó establecer en la propuesta de reforma constitucional de 1968. El presidente era el abogado Carlos Lleras Restrepo, quien contara con la valiosísima asesoría del profesor de la Universidad Externado de Colombia, el constitucionalista Carlos Restrepo Piedrahíta. ${ }^{4}$ Entre otros planteamientos de la institución política de la Corte Constitucional, finalmente se plasmaron en la Carta de 1991, en los artículos, 86, 116 y 241.

Por lo oportuno del tema, transcribo el siguiente pasaje doctrinal de una investigación de la profesora colombiana Tania Giovanna Vivas Barrera: ${ }^{5}$ "México cuenta con el honroso papel de haber sido el primer país en la historia constitucional moderna en consagrar el recurso judicial de amparo en la Constitución de 1857, posteriormente recogida en la actual Constitución Política de los Estados Unidos Mexicanos de 1917 como aval judicial de las garantías individuales, o según la novísima reforma para los derechos humanos ${ }^{6}$ de los ciudadanos mexicanos".

Haré un par de censuras, más como aporte al sano debate académico que como crítica infundada, a dos aspectos que en Colombia y México, me parece, pueden mejorarse en los trámites de estos magníficos mecanismos: el requisito de la inmediación para la procedencia de las acciones de tutela contra sentencias judiciales y la viabilidad del juicio de amparo contra normas generales.

\section{Origen internacional de la acción de tutela o de amparo}

Su arranque internacional surge en el artículo 25, "Protección Judicial”, numeral 1 de la Convención Americana de Derechos Humanos: "Toda persona tiene derecho a un recurso sencillo y rápido o a cualquier otro recurso efectivo ante

\footnotetext{
${ }^{3}$ Fernández Fernández, Vicente y Samaniego Behar, Nitza, "El juicio de amparo: historia y futuro de la protección constitucional en México", Revista IUS, vol. 5, No. 27. Disponible en: http://www.scielo.org.mx/scielo.php?script=sci_ arttextEtpid=S1870-21472011000100009\#nota

${ }^{4}$ Fue profesor del suscrito en la especialización de Derecho Constitucional Comparado de las universidades Externado de Colombia y Autónoma de Madrid.

${ }^{5}$ Vivas Barrera, Tania Giovanna, "El amparo mexicano y la Acción de Tutela colombiana. Un ejercicio de derecho constitucional comparado en Latinoamérica", Pensamiento Jurídico, No. 33. Disponible en: http://www.bdigital.unal.edu. co/36820/1/37883-168738-2-PB.pdf

${ }^{6}$ Luego de la reforma constitucional de junio 6 de 2011 al juicio de amparo, hubo un cambio de denominación al pasar de considerar el ámbito de protección del amparo de garantías individuales a la amplia categoría de derechos humanos.
} 
los jueces o tribunales competentes, que la ampare contra actos que violen sus derechos fundamentales reconocidos por la Constitución, la ley o la presente Convención, aun cuando tal violación sea cometida por personas que actúen en ejercicio de sus funciones oficiales". Obsérvese que es "judicial": ante los jueces. Distinta la regulación en el Pacto que regula la Jurisdicción universal o mundial y que se verá enseguida.

Es pertinente recordar la Opinión Consultiva OC-9/877 de la Corte Interamericana de Derechos Humanos (en adelante CIDH): "Como ya lo ha señalado la Corte, el artículo 25.1 de la Convención es una disposición de carácter general que recoge la institución procesal del amparo, como procedimiento sencillo y breve que tiene por objeto la tutela de los derechos fundamentales". La Corte, por unanimidad, dispuso que debía "considerarse como garantías judiciales indispensables no susceptibles de suspensión, según lo establecido en el artículo 27.2 de la Convención, el hábeas corpus (artículo 7.6), el amparo, o cualquier otro recurso efectivo ante los jueces o tribunales competentes (artículo 25.1), destinado a garantizar el respeto a los derechos y libertades cuya suspensión no está autorizada por la misma Convención".

De mayor cobertura es al respecto el Pacto Internacional de Derechos Civiles y Políticos. El artículo 2 lo consagra en este apartado: "Cada uno de los Estados Partes en el presente Pacto se compromete a garantizar que: a) Toda persona cuyos derechos o libertades reconocidos en el presente Pacto hayan sido violados podrá interponer un recurso efectivo, aun cuando tal violación hubiera sido cometida por personas que actuaban en ejercicio de sus funciones oficiales".

Véase que el recurso no tiene que ser judicial; sencillamente debe ser efectivo. ${ }^{8}$ Puede presentarse entonces ante el resto de autoridades. El artículo lo complementa así con todas las autoridades: "b) La autoridad competente, judicial, administrativa o legislativa, o cualquiera otra autoridad competente prevista por el sistema legal del Estado, decidirá sobre los derechos de toda persona que interponga tal recurso, y desarrollará las posibilidades de recurso 100 judicial; c) Las autoridades competentes cumplirán toda decisión en que se haya estimado procedente el recurso".

\footnotetext{
${ }^{7}$ Corte Interamericana de Derechos Humanos. Garantías Judiciales en Estados de Emergencia (artículos 27.2, 25 y 8 Convención Americana sobre Derechos Humanos). Solicitada por el Gobierno de la República Oriental del Uruguay. ${ }^{8}$ O'Donnell, Daniel, "Normativa, jurisprudencia y doctrina de los sistemas universal e interamericano", Alejandro Valencia Villa (ed.), Oficina en Colombia del Alto Comisionado de las Naciones Unidas para los Derechos Humanos, Bogotá, 2004, p. 471.
} 


\section{Un inconveniente en el ejercicio de la acción de tutela en Colombia}

Debo asumir que la acción de tutela tiene un protagonismo elocuente en la historia breve de la Corte Constitucional. La gente del común la identifica con la Constitución misma. Dicha corporación ha hecho un espléndido trabajo al respecto. Sin embargo, la obligatoriedad de la ley se ha vuelto exigible por la acción de tutela, pues los servidores públicos en materia de salud o de pensiones, por ejemplo, no actúan conforme a su deber funcional si no media la orden de un juez a través de una acción de esa naturaleza. En consecuencia, se desnaturaliza su esencia y se convierte en una figura cómplice para justificar el abuso de algunos funcionarios cuyo comportamiento raya en el delito de prevaricato.

Debo detenerme en una crítica severa a una postura jurisprudencial de la Corte Constitucional referente al conocimiento de las acciones de tutela por vías de hecho contra providencias judiciales respecto al requisito, inventado por la misma corporación, de la "Inmediación". Un poco de historia pone en contexto este tema que, estimo, no ha tenido el suficiente estudio. Fue inicialmente la Sala de Casación Civil de la Corte Suprema de Justicia la autoridad que calificó como "vías de hecho", conocidas como las actuaciones groseras de las autoridades públicas o más concretamente de las judiciales, contra los sujetos procesales y en porcentaje mayor de los sujetos pasivos de la acción penal en el trámite de los procesos con afectación del debido proceso y específicamente el derecho de defensa. La Corte Constitucional la retomó y luego le cambió el nombre por uno de mayor eufemismo pero de igual contenido: desde 2005 las llamó "causales de procedibilidad de la acción de tutela contra providencias judiciales”.

El Decreto 2591 de $1991^{9}$ reglamentó la Acción de Tutela. Destaco esta norma en especial, declarada inexequible: "Caducidad. La acción de tutela podrá ejercerse en todo tiempo salvo la dirigida contra sentencias o providencias judiciales que pongan fin a un proceso, la cual caducará a los dos meses de ejecutoriada la providencia correspondiente" (artículo 11). ${ }^{10}$ También el artículo 40 corrió igual suerte por unidad normativa.

\footnotetext{
${ }_{9}^{9}$ Dictado por el presidente de la república, en ejercicio de las facultades que le confiere el literal b) del artículo transitorio 5 de la Constitución Nacional, oído y llevado a cabo el trámite de que trata el artículo transitorio 6 ante la Comisión Especial. Fue una especie de Decreto Ley, donde fue revestido por facultades extraordinarias por la Asamblea Nacional Constituyente (Anc). Pero luego, en el corto tiempo, debió ser desde luego a través de una ley estatutaria, como lo establece en artículo 152. Tuvo apenas la bendición de la Comisión Especial, creada por la ANc, órgano lejano de tener un origen político, legitimidad entonces bien cuestionada.

${ }^{10}$ Norma declarada inexequible según Sentencia de la Corte Constitucional C-543 de 1992. Ministerio público José Gregorio Hernández Galindo.
} 
Para el Tribunal Constitucional, resultaba evidente la contradicción entre el establecimiento de un término de caducidad para ejercer la acción y lo establecido en el artículo 86 de la Constitución, el cual señala que podía intentarse en todo momento. Lo sorprendente fue la actitud tan conservadora. Adujo que no estaba dentro de las atribuciones del juez de tutela inmiscuirse en el trámite de un proceso judicial en curso, adoptando decisiones paralelas a las que cumple en ejercicio de su función. Añadió que era inadmisible que quien resuelve sobre la tutela extendiera su poder de decisión hasta el extremo de resolver sobre la cuestión litigiosa que se debate en un proceso o sobre el derecho controvertido. Concluyó la Corte que no procedía la acción de tutela contra ninguna providencia judicial, salvo el perjuicio irremediable aplicado en este evento como mecanismo transitorio supeditado a la decisión definitiva que adoptara el juez competente.

Hubo importantes salvamentos de voto. ${ }^{11}$ En juicioso y demoledor razonamiento, expusieron los magistrados disidentes que la sentencia que pone fin al proceso puede traducir un comportamiento del juez que irrogue agravio a los derechos fundamentales de una persona. Afirmaron que la acción de tutela es un medio procesal especial que complementa el derecho sustantivo constitucional, mediante la concesión de un arma poderosa a las personas que vean sus derechos fundamentales violados o desconocidos y tratándose de sentencias que vulneren estos derechos. Es un medio idóneo para depurar el eventual contenido de injusticia de la sentencia atacada. Evita, además, que ésta se torne inimpugnable e irrevocable, no obstante el flagrante desconocimiento del mínimo de justicia material que debe expresar toda sentencia y que sólo se da cuando se respetan y se hacen efectivos los derechos fundamentales.

En consecuencia, puede recaer sobre sentencias y providencias que pongan término a un proceso, proferidas por los jueces, tribunales, Corte Suprema de Justicia y el Consejo de Estado, cuando éstos vulneren o amenacen por acción u omisión cualquier derecho constitucional fundamental. Agregaron que la interpretación constitucional debía favorecer la coexistencia y máximo desenvolvimiento de los valores y fines constitucionales. En consecuencia, la sentencia de la Corte sacrificó el interés general, la justicia y la primacía de los derechos fundamentales en aras de una espuria seguridad jurídica, representada por las sentencias violatorias de los derechos fundamentales devenidas inimpugnables.

Así, la mayoría eludió todo esfuerzo interpretativo por conciliar la certeza jurídica -que privilegia en su sentencia por encima de cualquier otra consideración y valor- y la justicia -que la supedita a una subalterna necesidad de

\footnotetext{
${ }^{11}$ Ciro Angarita Barón, Eduardo Cifuentes Muñoz y Alejandro Martínez Caballero.
} 
"certidumbre jurídica"-. Anteponer la seguridad jurídica a la justicia material (mal interpretada, porque una comunidad donde la violación de los derechos fundamentales permanezca impune no reúne ninguna condición mínima de seguridad) es un recurso truculento inspirado únicamente en la lógica ciega del poder y en el inconfesado deseo de conservar feudos intocados dentro del Estado. Terminaron el discurso anotando la decisión mayoritaria, la cual desconoció el verdadero sentido y alcance del concepto de Estado social de derecho en el constitucionalismo contemporáneo, del cual la Constitución colombiana es tributaria. Como consecuencia, desatendió la importancia de la consagración de la acción de tutela como mecanismo jurídico que acentúa la fuerza normativa de la Constitución en todos los ámbitos de la vida jurídica nacional y como instrumento de limitación del poder.

La discusión se torna aguda y a menudo hostil cuando se trata la procedencia de acciones de tutela contra sentencias y con mayor énfasis de los fallos de los órganos de cierre, como la Corte Suprema de Justicia y Consejo de Estado. Estas autoridades no han ocultado su desgano; proponen incluso que sus decisiones sean intocables. La seguridad jurídica ha sido el eslabón de discusión más recurrente. Pero por supuesto la oculta pero evidente motivación es la soberbia al presumirse infalibles, quienes deberían dar ejemplo de sujeción a la majestad del derecho constitucional.

El siguiente apartado doctrinal de unos profesores ${ }^{12}$ colombianos es adecuado por su afinidad desde los escenarios nacionales e internacionales: "Así como la casación es el mecanismo mediante el cual se unifica la interpretación de la ley, la tutela o el amparo ante el tribunal constitucional son los mecanismos que garantizan uniformidad en la interpretación de la constitución, tomando en cuenta que distintas personas razonables pueden llegar a defender interpretaciones diversas sobre el alcance de una disposición constitucional”.

Un buen ejemplo que ilustra este argumento se encuentra en una sentencia de la Corte Suprema de Justicia de los Estados Unidos en 1816, en el caso Martin v Hunter's Lessee. En aquel momento, el tribunal supremo del estado de Virginia se opuso a la aplicación de una sentencia de la Corte Suprema de Justicia de los Estados Unidos con el argumento de que, debido a la cláusula federal, la Corte estatal era suprema en el Estado respectivo, y no podía recibir orden de nadie. Con todo y dicha oposición, la Corte Suprema de los Estados Unidos revocó la sentencia de la corte de Virginia, y defendió la competencia

\footnotetext{
${ }^{12}$ Garcia Villegas, Mauricio y Uprimny Yepes, Rodrigo, "La Reforma a la Tutela: ¿Ajuste o Desmonte?", Derecho Público, No. 15, 2002. Disponible en: http://www.escuelagobierno.org/inputs/ru_reformaTutela.pdf

Dicho artículo es fruto de una investigación que contó con la importante colaboración de Ethel Castellanos y Javier Tovar, quienes actuaron como asistentes de investigación.
} 
de la Corte Suprema Federal para revocar sentencias de los tribunales supremos de los estados. Luego de indicar algunos argumentos textuales e históricos que justificarían esa competencia, el juez Story, magistrado que redactó la sentencia (considerada como una de las más importantes de la historia de Estados Unidos), ${ }^{13}$ señaló el argumento decisivo:

Un motivo de otra naturaleza perfectamente compatible con el respeto más sincero por los tribunales estatales, induce a la concesión de un poder de apelación sobre sus decisiones. Este motivo es la importancia, incluso la necesidad de que se dicten decisiones uniformes en todos los Estados Unidos sobre todos los temas al amparo de la constitución. Jueces igualmente conocedores e íntegros en diferentes estados pueden interpretar en forma diversa la ley, un tratado o la propia Constitución. Si no existiera una autoridad con competencia para revisar esas sentencias discordantes y disonantes a fin de armonizarlas y unificarlas, las leyes, los tratados y la Constitución de los Estados Unidos serían diferentes en los diferentes estados y no tendrían tal vez nunca la misma interpretación, fuerza vinculante y eficacia en dos estados.

La Corte Constitucional ha precisado los requisitos de procedencia de la acción de tutela contra decisiones judiciales: a) que la cuestión que se discuta sea de trascendencia constitucional; b) que se hayan agotado los medios ordinarios y extraordinarios de defensa judicial, a menos que se pretenda evitar un perjuicio irremediable; c) que el recurso sea interpuesto en un término razonable para cumplir con el requisito de inmediatez; d) que la irregularidad procesal que se alegue tenga un impacto decisivo en la decisión; e) que el actor identifique los hechos de la vulneración; y f) que no se trate de una sentencia de tutela.

Respecto al requisito de Inmediatez, ${ }^{14}$ la jurisprudencia constitucional desarrolló su contenido. Señaló que si bien no existen límites temporales estrictos que limiten la interposición de una acción de este tipo, la misma resultaría viable

${ }^{13}$ Por ejemplo, Oliver Wendell Holmes, uno de los más prestigiosos magistrados y juristas de Estados Unidos, argumentó que esa sentencia era incluso más importante que el Fallo Marbruy vs. Madison, que inventó el control constitucional. Según Holmes, es posible construir una nación sin control de constitucionalidad de las leyes; pero resulta difícil lograr ese propósito sin la existencia de una instancia que unifique la interpretación de las normas básicas.

${ }^{14}$ Sentencia T-277 de 2015, Sala Primera de Revisión de la Corte Constitucional. Contra la Casa Editorial El Tiempo. Advirtió la Corte: "De conformidad con estos hechos, podría pensarse que se encuentra insatisfecho el requisito de inmediatez, toda vez que han transcurrido alrededor de doce (12) años desde el momento de la publicación hasta la solicitud de eliminación de la noticia ante el medio de comunicación. Sin embargo, la Sala considera que en el caso concreto el requisito se encuentra acreditado, en la medida que la vulneración alegada por la actora persiste en el tiempo, si se considera que la información aún se encuentra disponible para ser accedida a través de internet". 
siempre y cuando se intentara dentro de un término razonable y proporcionado, a partir de la vulneración o amenaza al derecho fundamental comprometido. La exigencia de este requisito tiene como fundamento: a) prevenir la afectación de derechos de terceras personas; b) verificar el respeto por la cosa juzgada; y c) dar vigencia al principio de seguridad jurídica. ${ }^{15}$

Sin embargo, la Corte ${ }^{16}$ ha inaplicado el principio de inmediatez en algunos eventos, cuando la violación de derechos persiste en el tiempo. En consecuencia, no existe así un término de caducidad de la acción de tutela en casos como de la salud y seguridad social en accidente laboral. ${ }^{17}$ Ese término razonable debe ser valorado por el juez de acuerdo con las circunstancias del caso concreto.

Pero la situación no deja de ser, en esos términos, demasiado contingente. Infiero que la vía de hecho cometida por un funcionario judicial pervive en el tiempo y nada en su paso imbatible puede sanearla, ni enervarla, ni matizarla y menos prescribir o caducar la acción para su reclamo. Piénsese, por ejemplo, en el derecho de defensa de un ciudadano condenado por un delito grave, quizá el único derecho de naturaleza absoluta, según los tribunales internacionales que interpretan y aplican los pactos de derechos humanos. 0 en la negativa sistemática al decreto o práctica de pruebas que determinaron una decisión adversa. 0 en el desconocimiento deliberado de los precedentes del órgano jurisdiccional de cierre o de la Corte Constitucional.

¿Cómo puede razonablemente la Corte Constitucional o las altas cortes o cualquier juez, en nuestro régimen mixto de control de constitucionalidad colombiano, rechazar el trámite de la acción de tutela o si se le impartió no concederla, con el argumento huérfano de no haberse hecho dentro de un "término razonable"?

0 más complejo aún, ¿cómo no establecer al menos un instrumento para determinar cuándo se puede escuchar al accionante cuando se supuso no hubo afectación del término para presentarla? En este evento siempre e inevitablemente habría una dosis evidente de arbitrariedad con claro menoscabo del actor en la acción constitucional. En aspectos tan cruciales para la persona del común, porque los poderosos están en otras latitudes, debe variarse sustancialmente la jurisprudencia de la Corte Constitucional en el entendido de que dicha exigencia sencillamente fuera suprimida. La seguridad de los coasociados no puede estar al libre arbitrio judicial con el riesgo de un tiránico gobierno de los jueces. Parafraseando a Lord Acton: "La forma más cierta por la cual podemos juzgar si un país es realmente libre es en la medida de la seguridad [social] de sus habitantes".

\footnotetext{
${ }^{15}$ Sentencia T-219 de 2012, M. P. Juan Carlos Henao Pérez.

${ }^{16}$ Sentencia T-332 de 2015, Sala Octava de Revisión de la Corte Constitucional.

${ }^{17}$ Sentencia T- 056 de 2014.
} 
Cuando un tribunal constitucional es tan folclórico en temas tan caros, preferiría uno, como jurista o simple analista, que fuera el legislador a través de una ley estatutaria quien instituyera que la procedencia de la acción de tutela fuera permanente. Con razón tal vez Pier Paolo Portinaro advertía:

Las Cortes constitucionales, en su papel de intérpretes de la Constitución, muestran, cada vez más, factores de innovación y producción del derecho concurrentes con el legislador. Está creándose la sospecha que las Constituciones contemporáneas sean rígidas respecto del poder legislativo y también frente a un hipotético superlegislador, pero se estén volviendo flexibles ante el poder político jurisdiccional de las Cortes supremas. ${ }^{18}$

\section{Una dificultad en el ejercicio de la acción de amparo en México}

Conforme al contenido del artículo 107 de la Constitución Política de los Estados Unidos Mexicanos, ${ }^{19}$ el recurso de amparo procedía contra violaciones al debido proceso al transgredirse las leyes del procedimiento. Inicialmente el precepto se refería a juicios civiles o penales: "En los juicios civiles o penales sólo procederá el amparo contra la violación de las leyes del procedimiento, cuando se afecten las partes substanciales de él y de manera que su infracción deje sin defensa al quejoso".

Luego se extendió a sentencias definitivas en materia civil cuando fuera adversa al tenor de la ley aplicable al caso y a su interpretación jurídica, y contra resoluciones no definitivas: "Cuando el amparo se pida contra la sentencia definitiva, en el juicio civil, sólo procederá, además del caso de la regla anterior, cuando, llenándose los requisitos de la regla segunda, dicha sentencia sea contraria a letra de la ley aplicable al caso o a su interpretación jurídica, cuando comprenda personas, acciones, excepciones o cosas que no han sido objeto del juicio, o cuando no las comprenda todas por omisión o negativa expresa.

106 Cuando se pida el amparo contra resoluciones no definitivas, según lo dispuesto en la fracción anterior, se observarán estas reglas en lo que fuere conducente".

Procede también el amparo en los juicios penales sobre la ejecución de la sentencia definitiva: "En los juicios penales, la ejecución de la sentencia definitiva contra la que se pide amparo, se suspenderá por la autoridad res-

\footnotetext{
18 "Se puede pensar que el autor se refiere a las cortes o tribunales constitucionales, y no a las cortes supremas entendidas como cortes de casación." Morell RICO, SANDRA, La Corte Constitucional. Un papel institucional por definir, Bogotá, Academia Colombiana de Jurisprudencia, 2001, p. 161.

${ }^{19}$ Que reformó la de 5 de febrero de 1857. Diario Oficial, tomo 5, No. 30, lunes 5 de febrero de 1917, pp. 149-161.
} 
ponsable, a cuyo objeto el quejoso le comunicará, dentro del término que fija la ley y bajo la protesta de decir verdad, la interposición del recurso, acompañando dos copias, una para el expediente y otra que se entregará a la parte contraria”.

Igual situación sucede con los juicios civiles: "En juicios civiles, la ejecución de la sentencia definitiva sólo se suspenderá si el quejoso da fianza de pagar los daños y perjuicios que la suspensión ocasionare, a menos que la otra parte diese contrafianza para asegurar la reposición de las cosas al estado que guardaban si se concediese el amparo, y pagar los daños y perjuicios consiguientes. En este caso se anunciará la interposición del recurso, como indica la regla anterior".

Los ordinales siguientes hasta el XI fijaron las pautas de procedimiento. Otro inciso se refirió a las infracciones de garantías primordiales: "La violación de las garantías de los artículos $16,{ }^{20} 19^{21}$ y 20 se reclamará ante el Superior Tribunal que la cometa o ante el juez de distrito que corresponde, pudiéndose recurrir en uno y otros casos a la Corte, contra la resolución que se dicte".

El ordinal XI consagró sanciones para la autoridad comprometida que insistiere en la repetición del acto reclamado: "Si después de concedido el amparo, la autoridad responsable insistiere en la repetición del acto reclamado o tratare de eludir la sentencia de la autoridad federal, será inmediatamente separada de su cargo y consignada ante el juez de distrito que corresponda, para que la juzgue".

Pero no había precepto que extendiera el juicio de amparo a la impugnación de normas por quebrantar cánones superiores. Era una defensa de la persona contra los abusos de funcionarios quienes actúan a nombre del Estado. Pablo Enrique Reyes Reyes ${ }^{22}$ se pronunció en estos términos: "la institución del amparo no es en realidad un sistema de defensa directo de la constitucionalidad, sino que más bien es la defensa primordial del individuo frente al Estado, que se resuelve en defensa primordial y eventual de la Constitución”.

Todo esto pareciera lógico en una inexorable ortodoxia constitucional y jurídica. Pero luego la Constitución mexicana reguló el juicio de amparo contra "normas generales". Esta situación introduce una variable de muy distinto significado y alcance en el juicio de amparo. Me parece particularmente un tema de notable importancia para el debate. Personalmente, no estoy de

\footnotetext{
${ }^{20}$ Artículo 16. Nadie puede ser molestado en su persona, familia, domicilio, papeles y posesiones, sino en virtud de mandamiento escrito de la autoridad competente, que funde y motive la causa legal del procedimiento.

${ }^{21}$ Artículo 19. Ninguna detención podrá exceder del término de tres días, sin que se justifique con un auto de formal prisión.

22 Reyes Reyes, Pablo Enrique, La acción de inconstitucionalidad, México, Oxford University Press, 2000, p. 73.
} 
acuerdo con dicha regulación. En mi formación en derecho constitucional (si se quiere un tanto ortodoxa o quizá conservadora), estimo que el escenario propio para impugnar o repudiar la aplicación de una norma de esas características debe ser el del control de constitucionalidad ante la autoridad constitucional habilitada expresamente para esa difícil misión. No comprendo que a través de un juicio o acción de amparo se logre fulminar la vida jurídica de una norma general.

Esa clase de juicios es un medio para alcanzar la inconstitucionalidad de una ley, por ejemplo, ante un Tribunal de la Federación. "Finalmente está el llamado amparo contra leyes, en el que cabe la posibilidad de impugnar cualquier norma general sin importar de dónde emanó, sino precisamente que su naturaleza jurídica es la de ser una norma jurídica, ya sean leyes en estricto sentido o bien reglamentos o disposiciones generales que emanan de la administración pública." ${ }^{23}$

La cuestión, infiero, no ha sido pacífica. El reconocido constitucionalista Héctor Fix-Zamudio opinó al respecto: "El juicio de amparo mexicano ha modificado su propósito original de tutelar exclusivamente los derechos fundamentales de carácter constitucional contra leyes o actos de cualquier autoridad, en un conjunto complejo de procesos, [que prácticamente] tutela todo el orden jurídico nacional". ${ }^{24}$ Otro autor también apuntó: "nuestro juicio de amparo nació y subsiste para proteger la Constitución, no en contra de ella misma, sino de los actos externos de cualquier autoridad". ${ }^{25}$

La Constitución que reformó la de 5 de febrero de $1857^{26}$ disponía: "Los tribunales de la Federación resolverán toda controversia que se suscite:

- Por leyes o actos de la autoridad que viole las garantías individuales.

- Por leyes o actos de la autoridad federal que vulneren o restrinjan la soberanía de los Estados.

- Por leyes o actos de las autoridades de éstos que invadan la esfera de la autoridad federal" (artículo 103).

${ }^{23}$ Fernández Fernández, Vicente y Samaniego Behar, Nitza, "El juicio de amparo: historia y futuro de la protección constitucional en México", Revista IUS, vol. 5, No. 27. Disponible en: http://www.scielo.org.mx/scielo.php?script=sci_ arttextEtpid=S1870-21472011000100009\#nota

${ }^{24}$ Vivas Barrera, Tania Giovanna, "El Amparo mexicano y la Acción de Tutela colombiana. Un ejercicio de derecho constitucional comparado en Latinoamérica", Pensamiento Jurídico, No. 33, p. 31. Disponible en www.revistas.unal. edu.co/index.php/peju/article/view/37883

${ }^{25}$ Martinez Cerda, Nicolás, La Corte Constitucional y la inconstitucionalidad de las normas constitucionales, México, Instituto Mexicano del Amparo, 1995, pp. 13-14. Disponible en: http://catarina.udlap.mx/u dl a/tales/documentos/ ledi/avila $\mathrm{c} \mathrm{cm} /$ capitulo2.pdf

${ }_{26}$ Diario Oficial de la Federación, tomo 5, No. 30, lunes 5 de febrero, 1917, pp.149-161. 
Adviértase cómo la norma se refería a "leyes". La Constitución actual ${ }^{27}$ la consagra con mayor amplitud en el artículo $103 .{ }^{28}$ Los tribunales de la federación resolverán toda controversia que se suscite:

- Por normas generales, actos u omisiones de la autoridad que violen los derechos humanos reconocidos y las garantías otorgadas para su protección por esta Constitución, así como por los tratados internacionales de los que el Estado Mexicano sea parte.

- Por normas generales o actos de la autoridad federal que vulneren o restrinjan la soberanía de los estados o la esfera de competencia del Distrito Federal.

- Por normas generales o actos de las autoridades de los estados o del Distrito Federal que invadan la esfera de competencia de la autoridad federal.”

Véase cómo ahora se refiere a "normas generales". Acerca de las “normas generales”, deduzco que se aplica a un universo normativo de gran cobertura donde desde luego estarían las leyes, pero también los decretos del presidente de la república, mediante los cuales reglamentaría las leyes; también normas de las autoridades administrativas centralizadas y descentralizadas; asimismo, las normas constitucionales e internacionales. Pero facilita más la tarea traer las expresiones de Rubén Sánchez Gil en un serio trabajo titulado La aplicabilidad de normas generales y su impugnación en amparo, ${ }^{29}$ acerca de lo que concibe como "norma general": "Aunque los ordenamientos legislativos, las "leyes" en el sentido formal más estricto, son el más claro ejemplo de las norma generales, este género abarca también otras especies como tratados internaciones, reglamentos, decretos, circulares administrativas y, en general, cualquier acto por el cual el Estado regule abstractamente determinados supuestos bajo determinadas circunstancias".

Creo que debe ser un Tribunal Constitucional o el órgano equivalente la Suprema Corte de Justicia de la Nación en México la autoridad legitimada para pronunciarse sobre algo tan relevante en una democracia como es la inconstitucionalidad de una ley. Pero además, ¿dónde queda el principio democrático del Congreso de la República al ostentar esa facultad tan relevante como es la reserva legal? Específicamente, la Constitución mexicana la consagra en los

\footnotetext{
${ }^{27}$ Última reforma publicada en el Diario Oficial de la Federación, 27 de enero de 2016.

${ }^{28}$ Artículo reformado en el Diario Oficial de la Federación, 31 de diciembre, 1994, 06 de junio, 2011.

${ }^{29}$ Sánchez GIL, Rubèn, La aplicabilidad de normas generales y su impugnación en amparo. Disponible en: http://biblio. juridicas.unam.mx/libros/7/3066/15.pdf
} 
artículos 71, 121 y 122, entre otros. La Suprema Corte de Justicia de la Nación es la legalizada para conocer: "De las acciones de inconstitucionalidad que tengan por objeto plantear la posible contradicción entre una norma de carácter general y esta Constitución" (artículo 105 ib.). Asimismo, "II. ${ }^{30}$ De las acciones de inconstitucionalidad que tengan por objeto plantear la posible contradicción entre una norma de carácter general y esta Constitución”.

El artículo 107 establece el procedimiento: "Cuando en los juicios de amparo indirecto en revisión se resuelva la inconstitucionalidad de una norma general por segunda ocasión consecutiva, la Suprema Corte de Justicia de la Nación lo informará a la autoridad emisora correspondiente.

Cuando los órganos del Poder Judicial de la Federación establezcan jurisprudencia por reiteración en la cual se determine la inconstitucionalidad de una norma general, la Suprema Corte de Justicia de la Nación lo notificará a la autoridad emisora. Transcurrido el plazo de noventa días naturales sin que se supere el problema de inconstitucionalidad, la Suprema Corte de Justicia de la Nación emitirá (siempre que fuere aprobada por una mayoría de cuando menos ocho votos) la declaratoria general de inconstitucionalidad, en la cual se fijarán sus alcances y condiciones en los términos de la ley reglamentaria.

Registro con inquietud la dicotomía en las funciones de la Suprema Corte de Justicia de la Nación en esas dos funciones, puesto que la invasión o la confusión o la usurpación de una y otra devienen inevitables. Me parece, por tanto, que en el pragmatismo de la cotidianidad del control de constitucionalidad y del juicio de amparo pueda generar más dificultades que soluciones.

La Ley de Amparo $^{31}$ enunció las normas generales para los efectos del amparo indirecto (artículo 107), una gran pléyade: tratados internacionales, la Constitución, leyes federales, Constituciones de los estados, el Estatuto de Gobierno del Distrito Federal, leyes de los estados y del Distrito Federal, reglamentos federales, entre otros.

En Colombia, cuando una norma general, una ley ordinaria por excelencia, contradice una de mayor calado (por ejemplo una ley estatutaria), ${ }^{32}$ la solución sería la inaplicación de la inferior y en su lugar la aplicación de la superior. Es lo que conocemos como la excepción de inconstitucionalidad, en virtud del artículo 4 de la Constitución Política, ${ }^{33}$ con mayor razón cuando es ésta la

\footnotetext{
${ }^{30}$ Párrafo reformado Diario Oficial de la Federación, 22 de agosto de1996.

${ }^{31}$ Reglamentaria de los artículos 103 y 107 de la Constitución mexicana publicada en el Diario Oficial de la Federación el 2 de abril de 2013.

${ }^{32}$ Artículo 152 de la Constitución Política.

33 "La Constitución es norma de normas. En todo caso de incompatibilidad entre la Constitución y la ley u otra norma jurídica, se aplicarán las disposiciones constitucionales. Es deber de los nacionales y de los extranjeros en Colombia acatar la Constitución y las leyes, y respetar y obedecer a las autoridades."
} 
transgredida directamente. En mi entender, en México podría ser parecida la solución y más técnico y expedito aún que a través de un juicio de amparo, se haría en cambio por medio de un control de convencionalidad.

He defendido ${ }^{34}$ en otros escenarios académicos este medio de control difuso tan importante en la actualidad:

Corolario del discurso anterior, se impone a todos los operadores jurídicos, en especial a los de la judicatura, aplicar el control de convencionalidad en la solución de los problemas del derecho, concretándolos a partir de eventos específicos, consonante con las reglas establecidas en los estándares internacionales en relación con el derecho internacional de derechos humanos, derecho internacional humanitario y derecho penal internacional, aunado a la jurisprudencia y doctrina de los organismos internacionales que aplican e interpretan esa normatividad, sumado también a la jurisprudencia y doctrina nacionales.

Juan Carlos Hitters ${ }^{35}$ definió así el control de convencionalidad: "es un mecanismo que debe ser llevado a cabo, primero por los cuerpos judiciales domésticos, haciendo una 'comparación' entre el derecho local y el supranacional, a fin de velar por el efecto útil de los instrumentos internacionales, sea que surja de los tratados, del iuscogens o de la jurisprudencia de la Corte Interamericana de Derechos Humanos; y luego esa tarea debe ser ejercida por la Corte Interamericana de Derechos Humanos si es que el caso llega a sus estrados". La CIDH le imprimió vida jurídica al "Control de Convencionalidad" en el año 2006 en el Caso Almonacid Arellano vs. Chile. ${ }^{36}$ Con relación al deber ser de las autoridades nacionales del orden judicial, manifestó:

La Corte es consciente que los jueces y tribunales internos están sujetos al imperio de la ley y, por ello, están obligados a aplicar las disposiciones vigentes en el ordenamiento jurídico. Pero cuando un Estado ha ratificado un tratado internacional como la Convención Americana, sus jueces, como parte del aparato del Estado, también están sometidos a ella, lo que les obliga a velar porque los efectos de las disposiciones de la

\footnotetext{
${ }^{34}$ Echeverri Quintana, Eudoro, Acercamientos al control constitucional. Temática inacabada, Bogotá, Ibáñez Universidad Libre Seccional Pereira, 2014, pp. 242 y ss.

${ }^{35}$ HitteRs, JuAn Carlos, "Control de Constitucionalidad y Control de Convencionalidad. Comparación. (Criterios fijados por la Corte Interamericana de Derechos Humanos)". Disponible en: http://www.scielo.cl/pdf/estconst/v7n2/art05. pdf

${ }^{36}$ Caso Almonacid Arellano vs. Chile. Excepciones preliminares, fondo, reparaciones y costas. Sentencia de septiembre 26 de 2006. Serie C No. 154, párrafos 123 a 125.
} 
Convención no se vean mermadas por la aplicación de leyes contrarias a su objeto y fin, y que desde un inicio carecen de efectos jurídicos. En otras palabras, el Poder Judicial debe ejercer una especie de "control de convencionalidad” entre las normas jurídicas internas que aplican en los casos concretos y la Convención Americana sobre Derechos Humanos. En esta tarea, el Poder Judicial debe tener en cuenta no solamente el tratado, sino también la interpretación que del mismo ha hecho la Corte Interamericana, intérprete última de la Convención Americana.

La $\mathrm{CIDH}^{37}$ dispuso que la obligación de cumplir con el control de convencionalidad fuera para todas las autoridades públicas y no solamente para las judiciales. De la misma forma deberían proceder oficiosamente o a título motu proprio.

Cuando un Estado es Parte de un tratado internacional como la Convención Americana, todos sus órganos, incluidos sus jueces, están sometidos a aquél, lo cual les obliga a velar por que los efectos de las disposiciones de la Convención no se vean mermados por la aplicación de normas contrarias a su objeto y fin, por lo que los jueces y órganos vinculados a la administración de justicia en todos los niveles están en la obligación de ejercer ex officio un "control de convencionalidad" entre las normas internas y la Convención Americana, evidentemente en el marco de sus respectivas competencias y de las regulaciones procesales correspondientes y en esta tarea, deben tener en cuenta no solamente el tratado, sino también la interpretación que del mismo ha hecho la Corte Interamericana, intérprete última de la Convención Americana. $^{38}$

La $\mathrm{CIDH}^{39}$ reiteró su precedente concretándolo en dos semblantes: “(i) Procede 'de oficio' sin necesidad de que las partes lo soliciten; y (ii) debe ejercerse dentro del marco de sus respectivas competencias y de las regulaciones procesales correspondientes, considerando otros presupuestos formales y materiales de admisibilidad y procedencia”.

\footnotetext{
${ }^{37}$ Caso Gelman vs. Uruguay, Sentencia de 24 de febrero de 2011 (fondo y reparaciones).

${ }^{38} \mathrm{Cfr}$. Caso Almonacid Arellano y otros vs. Chile. Excepciones preliminares, fondo, reparaciones y costas. Sentencia de 26 de septiembre de 2006. Serie C, No. 154, párr. 124; Caso Gomes Lund y otros (Guerrilha do Araguaia), supra nota 16, párr. 176, y Caso Cabrera García y Montiel Flores, supra nota 16, párr. 225.

${ }^{39}$ Corte Interamericana de Derechos Humanos, Caso Trabajadores Cesados del Congreso (Aguado Alfaro y otros) Vs. Perú, Sentencia de 24 de noviembre de 2006 (Excepciones Preliminares, Fondo, Reparaciones y Costas).
} 
Valga advertir que México hace parte de la jurisdicción interamericana de la Convención Americana de Derecho Humanos; la ratificó y adhirió el 3 de febrero de 1981. Entre las reservas las potestades no tocaron este aspecto. Ha habido jueces ilustres en la CIDH como Héctor Fix-Zamudio y Sergio García Ramírez. Insisto que esta nación ha hecho un invaluable aporte al derecho constitucional mundial.

En esta ruta, la profesora mexicana Mónica Arali Soto Fregoso ${ }^{40}$ hizo estas apreciaciones en materia electoral: "En relación a los dos últimos puntos [se refería al control de convencionalidad ex officio], es preciso comentar que la propia scun, estableció los pasos para llevar a cabo el control de convencionalidad ex officio, los cuales se enumeran a continuación:

- Interpretación conforme en sentido amplio, lo que significa que todos los jueces del país deben interpretar el orden jurídico a la luz y conforme a los derechos humanos reconocidos en la Constitución y en los tratados internacionales.

- Interpretación conforme en sentido estricto, es decir cuando haya varias interpretaciones jurídicamente válidas, los jueces deben preferir la que hace la ley acorde a los derechos humanos reconocidos en la Constitución y en los tratados internacionales firmados y ratificados por México.

- Cuando las alternativas anteriores no son posibles, inaplicación de la ley"

También, y en igual bitácora, el jurista mexicano Adrián Joaquín Miranda Camarena, ${ }^{41}$ acerca del papel del juez nacional, destacó que era garante del derecho internacional de los derechos humanos, realidad predicable desde la reforma constitucional en México en materia de derechos humanos de 2011. Esta es razón para aseverar que: "con ello, la introducción de los principios interpretativos conforme y pro persona, los órganos jurisdiccionales tienen la obligación, sin importar si son jueces locales o federales, de aplicar lo establecido en los tratados internacionales, normas supranacionales, y de interpretar las leyes nacionales con arreglo en los primeros para velar siempre por la protección más amplia de los derechos de las personas”.

\footnotetext{
${ }^{40}$ Soto Fregoso, Mónica Araul, "El ejercicio del control de convencionalidad por jueces mexicanos", en Eduardo Andrés Velandia Canosa (dir.), Derecho Procesal Constitucional, Bogotá, Legis - Universidad Santo Tomás, mayo de 2015, p. 63.

${ }^{41}$ Miranda Camarena, Adrián Joaquin, "El juez mexicano como garante del derecho internacional de los derechos humanos", en Eduardo Andrés Velandia Canosa (dir.), Derecho Procesal Constitucional, Bogotá, Legis - Universidad Santo Tomás, 2015, p. 562.
} 


\section{Conclusiones}

La veterana acción de amparo originaria de México, en el escenario mundial, merece todos los elogios y constituye imperativa enseñanza para los Estados aprendices en esta clase de instrumentos garantes de derechos y garantías. En Colombia, en cambio, la acción de tutela es demasiado joven; tiene la tierna edad de la Constitución Política de 1991. Pero su importancia es de tal magnitud que cualquier profano la identifica con esta Carta.

Las ventajas de ambas instituciones jurídicas son colosales. Sin embargo, el propósito de este estudio no fue destacar tan innumerables virtudes, sino hacer unos juicios críticos, no como expresión de una feroz censura, sino para explorar algunas soluciones con la finalidad de mejorar esos aspectos problemáticos dentro de una discusión pluralista.

En Colombia, la acción de tutela procede contra sentencias o providencias en general, cuando éstas incurren en evidentes vías de hecho, en el entendido de que vician el debido proceso como derecho fundamental. Es el relativo a la exigencia jurisprudencial de la Corte Constitucional de la inmediación, que consiste en que no puede ejercitarse ese mecanismo si ha pasado un tiempo que esa corporación caprichosamente designa como "prudencial", distinto, en todo caso, a lo que internacionalmente se entiende como el "Plazo razonable", derivado del instrumento de la CIDH al respecto.

La propuesta en esa hoja de ruta consiste en que ese requisito no impida su integro ejercicio, porque desnaturaliza la pretensión a nivel de la jurisdicción interamericana, para no mencionar la universal de Naciones Unidas de garantizar el "Recurso efectivo". Si uno o varios derechos fundamentales se violentaron con un proceso pecaminoso que concluyó en una sentencia que corrió con la suerte del fruto prohibido o envenenado, el tiempo por su solo transcurso no puede sanearlo ni enmendarlo porque el pecado mortal lo acompañará hasta que una autoridad judicial no lo redima.

En México, la regulación sobre la procedencia del juicio de amparo fue lógica en la perspectiva de su sensato ejercicio. La situación problemática a mi juicio comenzó cuando la Constitución mexicana la extendió al reproche de las "normas generales". Considero que a partir de ese momento su contenido varió sustancialmente el universo jurídico. El teatro idóneo para esa clase de querella, como la impugnación o cuestiones relativas a la aplicación de una norma de esas tipologías, es el del control de constitucionalidad ante el Tribunal Constitucional o autoridad que haga sus veces. No vislumbro que a través de una acción de amparo, por buena reputación que ostente, se persiga exterminar la vida jurídica de una norma general. 
La invitación afable que hago en este estudio es que a través de la excepción de inconstitucionalidad, como la conocemos en Colombia, se inaplique la norma inferior y en su lugar se aplique la noma superior que esté en consonancia con la Constitución Política o con la normatividad derivada del derecho internacional. En su defecto, sugiero que se haga uso del control de convencionalidad que, por suerte, entró en sociedad en la judicatura y específicamente en México, como lo aduje y demostré igualmente con estudios de profesores de esa nacionalidad.

Todas estas acciones, la de amparo y la de tutela, llamadas en conjunto o en forma genérica de amparo, constituyen ciertamente mecanismos de control de constitucionalidad entre muchos más. En el siguiente pasaje, un autor colombiano $^{42}$ pareciera darles el mismo alcance a todas. En mi sentir, esta postura es inexacta.

No obstante, a esta altura del presente trabajo pueden hacerse las siguientes afirmaciones al respecto: a) el recurso de amparo [se refería el autor citado al pie de página a la institución de España] y la acción de tutela no son las únicas garantías de los derechos fundamentales en el Estado constitucional contemporáneo. A ellas se suman otras de tipo judicial, como el recurso y la cuestión de inconstitucionalidad (acción pública de inconstitucionalidad en el caso colombiano) y el régimen general de tutela judicial de los derechos, amén de otras garantías de carácter extrajudicial, entre las que cuentan con especial relieve los mecanismos de participación democrática, la dinámica parlamentaría, los defensores del pueblo, etc.

Insisto, en un rigor científico o de purismo constitucional, que no debe la una usurpar el rol de la otra. Técnicamente es de mayor utilidad y provecho cada una en lo suyo.

Si vivimos en la aldea global de la cual hablaba el filósofo canadiense Herbert Marshall McLuhan, entonces con mayor razón la tendencia mundial ahora es la tutela multinivel de los derechos fundamentales. ${ }^{43}$ Parafraseando, si la humanidad hablara esperanto como único idioma mundial, según la pretensión del poliglota polaco Ludwik Lejzer Zamenhof, entonces lo ideal sería

\footnotetext{
${ }^{42}$ Osuna Patiño, Néstor Iván, Tutela y Amparo: Derechos protegidos. Estudio comparativo Colombia-España, Bogotá, Universidad Externado de Colombia, 1998, p. 283.

${ }^{43}$ Véase Miranda Bonilla, Haider, "El diálogo entre Cortes en el espacio convencional. Algunas cuestiones actuales", en Eduardo Andrés Velandia Canosa (dir.), Derecho Procesal Constitucional, Bogotá, Legis - Universidad Santo Tomás, 2015, pp. 341-360.
} 
ahora que la protección de los derechos fundamentales o humanos ${ }^{44}$ fuera un solo lenguaje constitucional en el planeta a través de lo que México instituyó como la acción de amparo.

\section{Bibliografía}

Diario Oficial, tomo 5, No. 30, lunes 5 de febrero de 1917

EcheVerri Quintana, Eudoro, Acercamientos al control constitucional. Temática inacabada, Bogotá, Ibáñez - Universidad Libre Seccional Pereira, 2014 Fernández Fernández, Vicente y Samaniego Behar, Nitza, "El juicio de amparo: historia y futuro de la protección constitucional en México”, Revista IUS, vol. 5, No. 27. Disponible en: http://www.scielo.org.mx/scielo.php?script=sci_ arttextCtpid=S1870-21472011000100009\# nota

García Villegas, Mauricio y Uprimny Yepes, Rodrigo, "La Reforma a la Tutela: ¿Ajuste o Desmonte?”, Derecho Público, No. 15, 2002. Disponible en: http:// www.escuelagobierno.org/inputs/ru_reformaTutela.pdf

Hitters, Juan Carlos, "Control de Constitucionalidad y Control de Convencionalidad. Comparación. (Criterios fijados por la Corte Interamericana de Derechos Humanos)". Disponible en: http://www.scielo.cl/pdf/estconst/v7n2/art05.pdf Martínez Cerda, Nicolás, La Corte Constitucional y la inconstitucionalidad de las normas constitucionales, México, Instituto Mexicano del Amparo, 1995, pp. 13-14. Disponible en: http://catarina.udlap.mx/u_dl_a/tales/documentos/ ledi/avila_c_cm/capitulo2.pdf

Miranda Bonilla, Haider, "El diálogo entre Cortes en el espacio convencional. Algunas cuestiones actuales”, en Eduardo Andrés Velandia Canosa (dir.), Derecho Procesal Constitucional, Bogotá, Legis - Universidad Santo Tomás, 2015

Miranda Camarena, Adrián Joaquín, "El juez mexicano como garante del derecho internacional de los derechos humanos”, en Eduardo Andrés Velandia Canosa (dir.), Derecho Procesal Constitucional, Bogotá, Legis - Universidad Santo Tomás, 2015.

Morelli Rico, SANDra, La Corte Constitucional. Un papel institucional por definir, Bogotá, Academia Colombiana de Jurisprudencia, 2001

O'Donnell, DANIEL, "Normativa, jurisprudencia y doctrina de los sistemas universal e interamericano", Alejandro Valencia Villa (ed.), Oficina en Colombia

\footnotetext{
${ }^{44}$ En el entendido que las declaraciones se rotulan como de derechos humanos y los pactos: la Declaración Americana de los Derechos y Deberes del Hombre (Bogotá, abril, 1948), la Declaración Universal de Derechos Humanos (Paris, diciembre, 1948), Pacto Internacional de Derechos Civiles y Políticos (Naciones Unidas, 1966), Convención Americana sobre Derechos Humanos (San José de Costa Rica, 1969).
} 
del Alto Comisionado de las Naciones Unidas para los Derechos Humanos, Bogotá, 2004

Osuna PATIÑo, NÉSTOR Iván, Tutela y Amparo: Derechos protegidos. Estudio comparativo Colombia-España, Bogotá, Universidad Externado de Colombia, 1998

Reyes Reyes, Pablo Enrique, La acción de inconstitucionalidad, México, Oxford University Press, 2000

SÁnCHEZ Gil, RuBÉn, La aplicabilidad de normas generales y su impugnación en amparo. Disponible en: http://biblio.juridicas.unam.mx/libros/7/3066/15.pdf Soto Fregoso, Mónica Arali, "El ejercicio del control de convencionalidad por jueces mexicanos”, en Eduardo Andrés Velandia Canosa (dir.), Derecho Procesal Constitucional, Bogotá, Legis - Universidad Santo Tomás, mayo de 2015

Vivas Barrera, Tania Giovanna, "El amparo mexicano y la Acción de Tutela colombiana. Un ejercicio de derecho constitucional comparado en Latinoamérica”, Pensamiento Jurídico, No. 33. Disponible en: http://www.bdigital. unal.edu.co/36820/1/37883-168738-2-PB.pdf 